\title{
El arte como saber: un acercamiento a la filosofía hegeliana del arte bello*
}

\author{
Art as knowing: an approach to the Hegelian \\ philosophy of beautiful art
}
A arte como saber: uma aproximação à filosofia hegeliana da arte bela

\section{Dra. Lelia Edith Profili**}

\begin{abstract}
RESUMEN
El presente trabajo se propone escudriñar el concepto de "arte" que resulta del movimiento del sistema hegeliano y ofrecer un acercamiento a las Lecciones sobre estética. La tesis central que orienta la argumentación propugna que el idealismo especulativo ofrece una alternativa tanto a la visión formalista y subjetivista del arte, cuanto a la comprensión del mismo como mero producto del juego de la fantasía humana, posicionando el problema estético en un campo nuevo por completo, en el ámbito específico de la filosofía del espíritu. El análisis procederá mediante una exégesis de fuentes seleccionadas, con un enfoque hermenéutico orientado a dilucidar el contenido especulativo del concepto del arte como saberse del espíritu. El curso del mismo conducirá a examinar, finalmente, la polémica tesis de Hegel acerca del fin del arte.
\end{abstract}

\section{SUMMARY}

This work proposes to scrutinize the concept of "art" that results from the movement of the Hegelian system and to offer an ap-
Palabras clave: arte, estética, Hegel, idealismo alemán

Keywords: art, aesthetics, Hegel, German idealism

1 Una versión preliminar del trabajo presentado aquí fue leída en las jornadas "Beethoven, Hölderlin y Hegel, a 250 años de su nacimiento", organizadas por el Centro de Filosofía Clásica Alemana de la Facultad de Filosofía y Letras de la U. N. Cuyo (Mendoza-Argentina), y celebradas el 12 y 13 de noviembre de 2020.

2 Argentina. Profesora, Licenciada y Doctora en Filosofía por la Universidad Nacional de Cuyo (Mendoza-Argentina). Actualmente se desempeña como Profesora Adjunta en la Cátedra de Metafísica de la misma Universidad. Contacto: leliaprof@hotmail.com. ORCID: 0000-0001-7427-3421 
proach to the Lessons on aesthetics. The central thesis that guides the argumentation advocates that speculative idealism offers an alternative both to the formalist and subjectivist vision of art, as well as to the understanding of it as a mere product of the game of human fantasy. This positions the aesthetic problem in a completely new field, in the specific area of the philosophy of the spirit. The analysis will proceed through an exegesis of selected sources, with a hermeneutical approach aimed at elucidating the speculative content of the concept of art as knowing about the spirit. The analysis will lead to finally examining Hegel's controversial thesis about the end of art.

\section{RESUMO}

O presente trabalho se propõe a examinar o conceito de arte que Palavras-chave: resulta do movimento do sistema hegeliano e oferecer uma aproximação às Lições sobre a Estética. A tese central que orienta a ararte, estética, Hegel, idealismo gumentação defende que o idealismo especulativo oferece uma alemão alternativa tanto à visão formalista e subjetivista da arte quanto à compreensão da mesma como mero produto da brincadeira da fantasia humana, posicionando o problema estético em um campo novo por completo, no âmbito específico da filosofia do espírito. A análise procederá mediante uma exegese de fontes selecionadas, com um enfoque hermenêutico orientado a elucidar o conteúdo especulativo do conceito da arte como conhecimento por parte do espírito. O curso do mesmo conduzirá a examinar, finalmente, a polêmica tese de Hegel sobre o fim da arte. 


\section{Introducción}

Antes de comenzar con el desarrollo de la argumentación y del trabajo exegético, vemos la necesidad de justificar la selección de las fuentes que han sido objeto fundamental del enfoque hermenéutico. Hasta la edición crítica de los apuntes (Nachschriften) de las lecciones sobre filosofía del arte, que comenzaron a publicarse en el último lustro del siglo XX, prácticamente la única fuente de la estética hegeliana fue la edición de H. G. Hotho, aparecida originalmente en la llamada

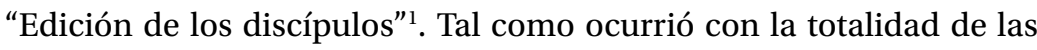
lecciones berlinesas, las Lecciones sobre estética fueron redactadas, articuladas y organizadas sobre la base de distintos apuntes de los discípulos de Hegel y, en especial, con apoyo en criterios de edición que, orientados intencionadamente hacia la homogenización e integración de diversos materiales, desembocaron en una mayor o menor adulteración de las fuentes originales ${ }^{2}$. Sin embargo, de este reparo no se sigue en ningún respecto la necesidad de desechar sin más estas fuentes de transmisión secundaria, como si se tratase de obras apócrifas. Muy bien lo expresa quien es uno de los principales responsables de la última edición histórico-crítica de las Nachschriften:

1 G. W. F. Hegel, Georg Wilhelm Friedrich Hegel's Werke. Vollständige Ausgabe durch einen Verein von Freunden des Verewigten. Bände X.1, X.2, X.3.

2 Las famosas Lecciones de Hegel fueron elaboradas sobre la base de dos tipos de fuentes principales, los manuscritos del propio Hegel (Manuskripte) y los apuntes tomados por sus alumnos (Nachschriften). La autenticidad de los primeros está fuera de toda duda, puesto que se trata de notas del propio Hegel que servían de apoyo para sus exposiciones orales. En la medida en que de ellos se conservaron solo unos pocos fragmentos, el problema con estas fuentes se refiere principalmente a su integridad. De los numerosos manuscritos de Hegel solo se retuvieron el Manuscrito de 1821 sobre Filosofía de la Religión, algunos fragmentos de sus notas para las Lecciones sobre Filosofía de la Historia e Historia de la Filosofía, que incluyen casi solamente las introducciones y dos fragmentos breves sobre estética. En lo que atañe a las Nachschriften, el problema estriba en evaluar su grado de autenticidad y pureza. En este respecto, los apuntes se han catalogado en tres grupos: 1) Mitschriften, apuntes tomados directamente del dictado en clase; aunque estilísticamente deficientes, reproducen más literalmente las exposiciones del maestro; 2) Reinschriften, apuntes que fueron pasados en limpio con posterioridad a la clase; suponen reelaboraciones estilísticas y completamientos por cotejo; 3) Ausarbeitungen, apuntes y notas que suponen una reelaboración personal por parte del redactor. V. al respecto W. Jaeschke. Hegel-Handbuch: Leben - Werk - Schule (en lo sucesivo = HB), 295-298 y el "Prefacio editorial" de R. Ferrara a G. W. F. Hegel. Lecciones sobre filosofía de la Religión. 1. Introducción y concepto de la religión, pp. xiii-xxix. En lo que respecta a la filosofía del arte, Hegel impartió sus célebres lecciones en los semestres de 1820/21, 1823, 1826 y 1828/29, siendo H. G. Hotho el encargado de la redacción y edición del texto incluido en la "Edición de los discípulos". 
...el resultado obtenido hasta el momento por la crítica de la edición de Hotho pone en evidencia la necesidad de una edición históricocrítica de todo el material. Solo la publicación histórico-crítica de todos los ciclos de lecciones, incluido el de 1828/29, remediará la edición de Hotho, rematará la necesaria investigación actual "dual" de los apuntes y de la edición y permitirá un juicio concluyente sobre su redacción.

Aún no puede ganarse, empero, una última certeza: pues muchos de los apuntes, en los que Hotho apoyó su edición, están desaparecidos. Ante todo, se han perdido los manuscritos de Hegel de las lecciones así como también los conjuntos posteriores de fragmentos. Por este motivo, el peligro de una estimación falsa acerca de la redacción de Hotho no se puede excluir completamente (Jaeschke 385-386).

Ante estos elementos de juicio, consideramos que no es posible, sin exponerse a una marcada parcialidad, desestimar sin más la edición de Hotho como inauténtica. En lugar de ello, la investigación de la estética hegeliana requiere hoy de un cotejo de la mencionada edición canónica con el estudio detenido de los apuntes, cuya publicación, por cierto, solo se ha completado recientemente ${ }^{3}$. El escaso número de apuntes conservados en su integridad así como la pérdida de los manuscritos del propio Hegel impiden prescindir por completo de la cuestionada edición de Hotho, que seguirá valiendo como una fuente imprescindible de la transmisión secundaria del pensamiento estético de $\mathrm{Hegel}^{4}$. Por esta razón y dado que nuestro objetivo prioritario estri-

3 Recién en el año 2020 se publicó la edición crítica de los apuntes del último ciclo de lecciones sobre filosofía del arte (1828/29) en G. W. F. Hegel, Gesammelte Werke. Band 28.3: Vorlesungen über die Philosophie der Kunst III. Nachschriften zum Kolleg des Wintersemesters 1828/1829. Los ciclos anteriores aparecieron respectivamente en Gesammelte Werke. Band 28.1: Vorlesungen über die Philosophie der Kunst I. Nachschriften zu den Kollegien der Jahre 1820/21 und 1823 (2015) y en Gesammelte Werke. Band 28.2: Vorlesungen über die Philosophie der Kunst II. Nachschriften zum Kolleg des Jahres 1826 (2018). Las primeras publicaciones de los cuadernos aprecieron en $1995 \mathrm{y}$ se sucedieron en los años subsiguientes: los apuntes de W. von Aschenberg, 1820/21 aprecieron en G. W. F. Hegel, Vorlesungen über Ästhetik. Berlin 1820/21. Eine Nachschrift; los de H. G. Hotho, 1823, en G. W. F. Hegel, Vorlesungen über die Philosophie der Kunst; los de P. von der Pfordten, 1826, en G. W. F. Hegel, Philosophie der Kunst; y los de F. C. H. V. von Kehler, 1826, en G. W. F. Hegel, Philosophie der Kunst oder Ästhetik.

4 Una posición diferente de la que aquí asumimos defiende A. Gethmann-Siefert, quien, en varios trabajos suyos, ha puesto seriamente en duda la fidelidad de la edición de Hotho. V. en especial su Einführung in Hegels Ästhetik, la Introducción de su edición del apunte de Hotho de 1823 (en G. W. F. Hegel, Vorlesungen über die Philosophie der 
ba en brindar un acercamiento introductorio de la filosofía hegeliana del arte, la exégesis se aplicará a los textos de la edición de Hotho ${ }^{5}$, a la vez que evitará aquellos pasajes cuya problematicidad resulte destacada por la crítica especializada o, en su defecto, justificará su significación y relevancia.

Delimitada y justificada la selección de fuentes primarias, podemos comenzar nuestra aproximación a la comprensión hegeliana del arte con las observaciones preliminares de la Introducción de las Lecciones:

Estas lecciones están dedicadas a la estética; su objeto es el vasto reino de lo bello; más precisamente, su campo es el arte, el arte bello. Sin embargo, para este objeto, no es completamente adecuado el nombre de "estética", pues él designa en rigor la ciencia de la sensibilidad, de la sensación [...] En razón de lo inadecuado o, más propiamente, de lo superficial de este nombre se ha intentado acuñar otros, por ejemplo el de Kalística. Mas este se muestra también como insuficiente, ya que la ciencia aquí mentada no considera lo bello en general, sino solamente lo bello del arte. Nos damos por satisfechos con el nombre de "estética", porque como mero nombre resulta para nosotros indiferente [...] Pero, la verdadera expresión para nuestra ciencia es "filosofía del arte" y, de un modo más determinado, "filosofía del arte bello" .

El pasaje citado aporta varios elementos para empezar el acercamiento al pensamiento estético de Hegel. En primer lugar, permite posicionarlo a la luz del contexto histórico en el que está inserto: la

Kunst [1823], pp. XV ss.) y el Prólogo de la edición del apunte de Kehler de 1826 (en G. W. F. Hegel, Filosofía del arte o Estética. Verano de 1826. Apuntes de F. C. H. V. von Kehler, pp. 7 ss.). En este último escrito suyo sostiene: "A pesar de su incuestionado y persistente influjo, la edición de Hotho de la Estética de Hegel debe ser considerada como una base textual altamente problemática para una elucidación de su filosofía del arte que sea tan precisa desde el punto de vista histórico y filológico como filosóficamente exacta" (8). Esta postura ha encontrado también eco en los estudios sobre Hegel en español. V. por ejemplo los trabajos de I. Debernardi Cárcamo, principalmente, «Las lecciones sobre estética de Hegel: discrepancias fundamentales entre la edición de Hotho y los Nachschriften». En este artículo, el autor ofrece una sinopsis clara de las adulteraciones estructurales introducidas por Hotho en el texto de las Lecciones.

5 Hemos trabajado directamente sobre el texto de G. W. F. Hegel, Werke in zwanzig Bänden (en lo sucesivo se abrevia $\mathrm{W}$ y se cita seguido de un número romano que indica el tomo y uno arábigo que corresponde a la página), tt. XIII-XV.

6 W XIII, 13. Salvo que se indique lo contrario, todas las traducciones del alemán son de la autora. 
estética, como disciplina filosófica, había alcanzado en el siglo XVIII la significación de una "filosofía del arte"7. Ya no se trata en ella solo de una teoría acerca de la sensación ( $\alpha i ̋ \sigma \vartheta \eta \sigma ı)$ y del conocimiento sensorial, sino, antes bien, de una teoría acerca del arte mismo. Como figuras representativas en este campo pueden mencionarse aquí nombres como los de Baumgarten, Winckelmann, Lessing o Herder. Entendida como filosofía del arte, la estética es, en tiempos de Hegel, una disciplina relativamente reciente de la filosofía, pero también un campo fecundo de profundas reflexiones y de un intenso desarrollo. Como antecedente directo de la filosofía hegeliana del arte debe reconocerse a Schelling. En el System des transzendentalen Idealismus había asignado a la estética un lugar preponderante frente a la filosofía de la naturaleza y a la filosofía trascendental, sobre la base de que su objeto es superior al de estas disciplinas, a saber, el arte como intuición de lo absoluto. También debemos incluir a Schiller, cuyas Briefe über die ästhetische Erziehung des Menschen presentan la educación estética como el medio fundamental para reconciliar el hombre natural y el hombre ideal, la sensibilidad y la razón, la naturaleza y la libertad. Al formar las inclinaciones y los impulsos, ella permite que la naturaleza se vuelva racional. Lo bello es, para Schiller, esta concordancia de lo racional y lo sensible. Esta tesis localiza la esencia del arte en la unidad de lo universal y lo particular, de lo natural y lo espiritual, y anticipa de tal manera la comprensión hegeliana.

Pero, sobre todo, debemos recordar aquí a Kant, quien en su Kritik der Urteilskraft había vislumbrado ya como esencia de lo artístico la pura autorrelación racional, la libertad, y su conformidad con el conocimiento $^{8}$. Kant puso en evidencia el carácter eminentemente reflexivo del juicio estético: a diferencia del juicio determinante, propio de la

$7 \quad$ El incipiente debate estético del siglo XVIII surge con la marca de la oposición entre las posturas dominantes en aquella época, las del racionalismo y del empirismo. Según la concepción racionalista, la estética es una ciencia del conocimiento sensible (v. A. G. Baumgarten. Aesthetica); conforme con la comprensión empirista, en cambio, el conocimiento estético solo consiste en una investigación del origen subjetivo de las ideas de lo sublime y de lo bello, a partir del efecto fisiológico que las propiedades de determinados objetos producen en el organismo (v. E. Burke. Philosophical Enquiry into the Origin of our Ideas of the Sublime and Beautiful). Una descripción sintética y clara de las doctrinas aquí solo reseñadas puede consultarse en H. J. Sandkühler. Handbuch deutscher Idealismus, p. 297.

8 Cf. W XIII, pp. 83 ss. 
actividad teórica de nuestro entendimiento discursivo y que procede siempre subsumiendo lo particular dado en la intuición bajo la forma universal, el juicio estético es reflexionante ${ }^{9}$. Se trata en este caso de un tipo de juicio que no procede subsumiendo lo particular en la forma universal, sino, a la inversa, derivando lo particular desde lo universal como contenido en él. Este tipo de juicio, característico de un entendimiento no discursivo, resulta sin embargo necesario, según Kant, para juzgar acerca de ciertos objetos, como por ejemplo los procesos de la naturaleza orgánica y los objetos estéticos. Cuando se refiere a estos objetos, nuestro entendimiento no funciona de un modo discursivo, sino que juzga imitando el operar de un entendimiento intuitivo y, por este motivo, debe asentarse sobre un supuesto, sobre una hipótesis trascendental que la razón teórica no puede demostrar: la de la existencia de una causalidad teleológica por libertad. Bajo el principio trascendental de finalidad, la facultad de juzgar de modo reflexionante permite vincular el plano sensible-fenoménico con el inteligible, tendiendo el puente entre la racionalidad interior (el sustrato suprasensible de la naturaleza) y la existencia fenoménica exterior. La posibilidad de pensar una armonía entre la causalidad mecánica, propia del ámbito fenoménico, y la causalidad teleológica, propia del ámbito inteligible, se halla sujeta también a la hipótesis trascendental ${ }^{10}$.

9 V. I. Kant, Kant's Gesammelte Schriften „Akademieausgabe“ [en lo sucesivo = AA, seguido de número romano para indicar tomo y número arábigo correspondiente a la página] V, 179 ss.; en especial pp. 188 ss.

10 En la tercera Crítica ( $\$ 75$ ss.) Kant había pensado la posibilidad de articular dos formas de causalidad, la mecánica, que conoce el entendimiento, y la teleológica, que se verifica como un presupuesto trascendental de la razón. Este supuesto se muestra como necesario para explicar los fenómenos naturales allí donde el entendimiento no alcanza a comprender el objeto. La prueba de la posibilidad de la causalidad teleológica reside, para Kant, en la naturaleza orgánica. Cuando el entendimiento humano encuentra en la naturaleza un sistema en el que se manifiesta una cierta teleología, y a fin de juzgar sobre la posibilidad de una finalidad en los seres orgánicos, debe recurrir al presupuesto de una causa que obra conforme a fines, es decir, de modo inteligente: "según la condición propia de mis facultades de conocimiento, yo no puedo juzgar sobre la posibilidad de aquellas cosas y su producción [cosas naturales], sino cuando pienso una causa de ellas que obra conforme a propósitos, por ende, un ser que es productivo por analogía con la causalidad de un entendimiento"; "cuando debemos juzgar según [...] las condiciones y limitaciones de nuestra propia razón, no podemos más que poner como fundamento de la posibilidad de aquellos fines naturales un ser inteligente" (AA V, 397-398; 400). La comprobación de una cierta finalidad en la naturaleza no puede explicarse sino suponiendo una causa que se sirve de la causalidad mecánica para realizar sus propias formas y sus propios fines, esto es, una causa inteligente. Ahora bien, ese entendimiento capaz de unificar mecanicismo y teleología debería ser, de acuerdo con 
Desde estas premisas, lo bello presenta la forma de la finalidad sin la representación de un fin: es aquello en lo que no es posible distinguir entre el fin y el medio donde aquel se realiza. La definición kantiana destaca en lo bello el aspecto de la autofinalidad, de la unidad indisoluble entre medio y fin. El mencionado aspecto permitirá pensarlo finalmente como aquello que place sin interés, así como precisar la relación del sujeto con él como una relación libre. En gran medida la estética hegeliana se muestra deudora de estas tesis de Kant; sin embargo, a diferencia de Hegel, aquel redujo lo estético a la función del juicio reflexionante, más precisamente al juicio de gusto, que no implica una forma de conocimiento objetivo sino una reflexión subjetiva en la que el objeto es referido al sujeto y a su sentimiento de complacencia o gusto.

Hegel, por el contrario, posiciona el problema estético en un campo nuevo por completo, en el ámbito específico de su filosofía del espíritu, $y$, con ello, la perspectiva estética cambia de un modo decisivo: por una parte, el arte muestra una historicidad que le resulta connatural. Puesto que lo espiritual es una existencia intrínsecamente histórica, la filosofía del arte deberá incluir como un momento integral el tratamiento de los momentos determinados en su desenvolvimiento histórico; además, su aparecer objetivo manifiesta una lógica que se corresponde también con la vida del espíritu en otros planos —objetivo, ético, religioso, filosófico-. Por otra parte, desde este posicionamiento filosófico-espiritual, queda relativizado el puesto especial atribuido al genio, a la subjetividad singular como instancia originaria del arte. Si bien para Hegel no hay arte que no involucre la subjetividad del artista, la obra de arte no es simplemente el producto de un sujeto individual determinado, menos aún es ella un mero reflejo de la sociedad de su-

Kant, un entendimiento no discursivo como el entendimiento humano, sino intuitivo, puesto que solo un entendimiento intuitivo, que proceda de lo universal a lo particular, del todo a las partes, podría conjugar la causalidad mecánica y la teleológica. En esta presuposición trascendental de un entendimiento intuitivo se piensa el fundamento de un orden inteligible de la naturaleza y de su unidad mecánica y teleológica. Desde ella, la naturaleza puede ser pensada como un organismo que se sirve de la causalidad mecánica para la realización de fines. Por ello mismo la argumentación kantiana desembocará en la identificación de este entendimiento intuitivo con el "sustrato suprasensible de la naturaleza". Precisamente, con este contexto general de una indagación sobre el vínculo entre lo fenoménico y lo inteligible, entre lo sensible y lo suprasensible, Kant enlaza su doctrina del juicio reflexionante y sus tesis principales sobre lo bello como identidad de fin (lo universal) y medio (lo particular), o sea como "finalidad sin fin" (AA V, 241). 
jetos. Quien en ella se expresa es, antes bien, el espíritu absoluto, cuyo contenido es reconocido en el seno de una mismidad subjetiva:

La figura de este saber [...] es por una parte un disgregarse en una obra de existencia exterior común, en el sujeto que la produce y en el sujeto que la intuye y venera; por otra parte, es la intuición concreta y representación del espíritu absoluto en sí como [intuición y representación] de lo ideal, es decir, de la figura concreta, nacida del espíritu subjetivo, en la cual la inmediatez natural es solamente signo de la idea, y para cuya expresión [aquella inmediatez] está transfigurada por el espíritu imaginativo $[\ldots]^{11}$.

Aun cuando el arte resulte impensable sin la producción libre de la subjetividad, sin la actividad del "espíritu imaginativo" - tal como Hegel se expresa en este pasaje-, aun cuando él se comprenda como la forma subjetiva del fenómeno del espíritu absoluto, no se trata en ningún caso de un simple producto del espíritu subjetivo. Es, por cierto, esta tesis la que justifica cabalmente por qué, según Hegel, resulta más adecuado hablar de "filosofía del arte" que de "estética". Del mismo modo que la religión y la filosofía, el arte no puede ser explicado desde la mera sensación, sentimiento o percepción subjetiva de determinados individuos. Esto supone, además, la necesidad de desechar el error que consiste en interpretar estas producciones espirituales desde objetivos individuales, contingentes y relativos, exteriores a ellas, o como instancias solo finitas resultantes de la actividad del individuo. En el marco de la filosofía hegeliana, el arte, la religión y la filosofía, se muestran como figuras esenciales del saberse del espíritu. Pensarlas como fenómenos del espíritu absoluto implica encontrar en ellas el mostrarse o el revelarse mismo de lo espiritual en la existencia finita y exterior.

La argumentación subsiguiente tendrá como objetivo prioritario precisar este concepto del arte que resulta del movimiento del sistema hegeliano, para demostrar hasta qué punto el idealismo especulativo ofrece una alternativa tanto a la visión formalista y subjetivista del arte cuanto a la comprensión del mismo como mero producto del juego de

11 G. W. F. Hegel. Enzyklopädie der philosophischen Wissenschaften im Grundrisse (1830), § 556. En: G. W. F. Hegel, Gesammelte Werke (= GW) 20, 543. Todas las citas de la Enciclopedia de 1830 seguirán el texto aquí referido y se indicarán señalando tomo (20), página (número arábigo) y parágrafo (entre corchetes). 
la fantasía humana, es decir, un aporte frente a la disyuntiva, dada en la época de Hegel, entre Kantismo y Romanticismo en el ámbito de la estética filosófica ${ }^{12}$.

\section{El arte como figura de la autoconciencia del espíritu}

Las Lecciones sobre estética de Hegel elucidan el concepto del "arte" desde una óptica doble: por un lado, desde su concepción como fenómeno del espíritu absoluto y, por ende, como una figura paradigmática del autoconocimiento del espíritu; por otro, a la luz de la idea de "belleza", la cual resulta clave para poder pensarlo como el "vasto reino de lo bello". En las siguientes líneas ofreceremos un acercamiento a ambos enfoques, para mostrar su vínculo conceptual y su unidad teórico-filosófica.

Tanto la Enciclopedia de las ciencias filosóficas cuanto el texto de las Lecciones parten de la ubicación del fenómeno del arte en la esfera de las actividades superiores del espíritu:

...el arte bello [...] solo cumple su tarea suprema cuando se posiciona en el círculo común con la religión y la filosofía, y solo es una manera de expresar y de traer a la conciencia lo divino, los intere-

12 Como portavoz de la visión formalista del arte, concentrada en las prescripciones y reglas de la producción artística, Hegel cita el trabajo de J. H. Meyer, Historia de las artes plásticas en Grecia (1824-1836). También, como ejemplos tomados de la Antigüedad, menciona la Poética de Aristóteles, el Ars Poetica de Horacio y el trabajo Sobre lo sublime de Longino (W XIII, 29 ss.). Del lado de la consideración subjetivista, Hegel remite sobre todo a las obras de Moses Mendelssohn (52 ss.), aunque caracteriza como tales, en general, a todas aquellas teorías estéticas que se focalizan en las sensaciones y afecciones subjetivas provocadas por el arte y, en particular, a las que tratan sobre el sentido de gusto (Geschmack) como "sentido formado de la belleza" (54); en esta última acepción, sería la doctrina kantiana la representante más lograda de la mentada concepción subjetivista del arte. De allí que Hegel la declare el "punto de partida para la verdadera concepción de lo bello artístico, aun cuando esta concepción solo pueda lograrse superando las deficiencias kantianas y comprendiendo en una forma más elevada la verdadera unidad de necesidad y libertad, de lo particular y lo universal, de lo sensible y lo racional" (89). En lo que atañe a la última tesis mencionada aquí, a saber, la que sostiene que el arte nace del libre juego de la fantasía, ella describe, en sus rasgos generales, la posición del Romanticismo temprano. Representativas resultan en este respecto y a modo de ejemplo las palabras de F. Schlegel en su "Discurso sobre la mitología" de 1800: "éste es el principio de toda poesía: anular el curso y las leyes de la razón pensante y volvernos a poner de nuevo en el bello desorden de la fantasía, en el caos originario de la naturaleza humana" (Schlegel 123). 
ses más profundos del hombre, las verdades más abarcadoras del espíritu ${ }^{13}$.

Pensado desde sus fundamentos especulativos, el arte, junto con la religión y la filosofía, se muestra como una figura de la autorrelación por la cual el espíritu se refiere a sí mismo y se conoce. Esto significa que no nace de objetivos singulares o meramente subjetivos, sino que está enraizado en la misma estructura racional del espíritu, que entraña el desdoblamiento, la exteriorización y la objetivación. Actúan como un presupuesto de estas afirmaciones las tesis básicas desde las cuales Hegel desarrolla su filosofía del espíritu: la Enciclopedia de 1830 presenta la esencia de lo espiritual en una remisión explícita al "concepto del concepto" ${ }^{14}$ como su fundamento lógico. El espíritu se define allí como "la idea que ha alcanzado su ser para sí" y como la "negatividad absoluta", que ha restaurado su identidad en su "retornar desde la naturaleza"15. La negatividad absoluta había sido el tema principal de la lógica del concepto, en la medida en que ella mienta el movimiento de determinación y diferenciación inmanente del concepto mismo. En esta "negatividad absoluta", esto es, en la libertad, reside el núcleo lógico de lo espiritual. El mismo consiste en la autodiferenciación dialéctica que reduce la otredad a un momento asumido.

En esta estructura racional del espíritu, que implica necesariamente la negación, la escisión y el extrañamiento como medios de su autoconocimiento, Hegel encuentra el fundamento último del arte. Y esto significa que la obra de arte es una objetivación de la espiritualidad humana que brota de la misma estructura lógica del espíritu. En este sentido, Hegel propugna lo siguiente:

La necesidad universal del arte reside en lo racional, que consiste en que el hombre debe elevar a la conciencia espiritual el mundo interior y exterior como un objeto, en el cual reconoce su propia mismidad (Selbst). Él satisface la necesidad de esta libertad espiritual, en la medida en que internamente torna para sí lo que es y realiza de modo externo este ser para sí [...], por otro lado, en la medida en que en esta duplicación se intuye y conoce. Esta es la 
racionalidad libre del hombre, donde encuentran su fundamento y su origen necesario todo obrar y todo saber, así como también el $\operatorname{arte}^{16}$.

El arte se describe aquí como una expresión del proyecto propiamente humano de transformar la mera naturaleza en un espacio espiritual y, con ello, de convertir el mundo en un mundo de y para el hombre. La obra de arte se posiciona así a modo de medio reconciliador "entre la sensibilidad inmediata y el pensamiento ideal" ${ }^{17}$. La misma definición de la belleza artística, como "figura concreta [...] nacida del espíritu"18, confirma que la función preeminente del arte estriba en transformar lo sensible-material en una obra de índole espiritual. En él, el espíritu imprime su sello en lo natural, y lo sensible se ofrece solo como punto de referencia donde él se reafirma y produce a sí mismo. Por esta razón también, la obra artística posee para Hegel una significación "lógico-metafísica" ${ }^{19}$ fundamental, a saber, la de salvar la separación entre lo natural y lo espiritual: "[El espíritu] produce desde sí mismo las obras del arte bello como el primer medio que reconcilia lo meramente exterior, sensible y perecedero con el pensamiento puro, la naturaleza y realidad finita con la libertad infinita del pensar conceptual" $^{20}$.

$\mathrm{Al}$ resultar de la transfiguración de lo sensible y exterior en un producto del espíritu, en una materia conformada por su libertad, la obra de arte posee una realidad intrínsecamente espiritual. Hegel añade que ella alcanza la "verdadera existencia" y que presenta una "realidad superior" frente a la existencia perecedera y exterior del mundo natural. Precisamente, la suya es una realidad "nacida del espíritu" (geistgeborene Wirklichkeit) que destaca y hace aparecer el ritmo de lo racional, liberándolo de la accidentalidad y de la finitud de la existencia sensible exterior. En este sentido, se añade lo siguiente:

El arte separa la apariencia y el engaño de este mundo perecedero respecto del verdadero contenido de los fenómenos y les confiere una realidad superior, nacida del espíritu. Por lo tanto, lejos de ser

16 W XIII, 52.

17 W XIII, 60.

18 GW 20, $543[$ [ 556].

19 W XIII, 26.

20 W XIII, 21. 
mera apariencia, a los fenómenos del arte debe atribuírseles, frente a la realidad habitual, la realidad superior y la verdadera existencia $^{21}$.

Esta significación lógico-metafísica libera a la obra artística del prejuicio de ser mera apariencia, es decir, del prejuicio de que la apariencia o aparecer sensible es solo lo no verdadero. Para comprender cabalmente esta determinación es necesario recurrir a las tesis hegelianas de la lógica de la reflexión ${ }^{22}$. Según ellas, la apariencia (Schein) no es simplemente lo no verdadero, sino una reflexión positiva de lo verdadero en cuanto tal. El aparecer es la superación de la existencia inmediata y meramente exterior en una relación, cuyo fundamento es la potencia de lo lógico (Hoffmann 446). De este modo queda establecida la íntima vinculación entre lo bello artístico y la verdad. No se trata en él de un simple juego subjetivo de la fantasía humana o de un fenómeno superficial carente de toda sustancia. La tarea y finalidad última del arte estriban en descubrir la verdad de la existencia:

El arte tiene la determinación de comprender y exponer la existencia en su aparecer fenoménico como algo verdadero [...] reconduce lo que en la existencia está oscurecido por la contingencia y la exterioridad a esta armonía con su verdadero concepto. [...] La naturaleza del ideal artístico debe buscarse en esta reconducción de la existencia exterior a lo espiritual, en virtud de la cual el fenómeno exterior, en cuanto acorde al espíritu, se torna el descubrimiento del mismo ${ }^{23}$.

Es decir, el arte tiene la virtud de revelar la verdadera realidad en la existencia contingente y exterior, de poner de manifiesto en ella su comunidad con lo espiritual y, por cierto, desde la apropiación y superación por parte del espíritu, de eso que, a primera vista y sin serlo, se presenta como realidad verdadera. En todo aquello que para la conciencia prosaica se muestra como algo finito, perecedero, exterior y meramente material, la actividad artística pone al descubierto su fondo o fundamento lógico; lo libera de las limitaciones, atrofias y mutilaciones que este sufre en la existencia y, de tal manera, reafirma

21 W XIII, 22

22 Cf. GW 11, 244 ss.

23 W XIII, 205-206. 
al espíritu por sobre la finitud de las contingencias exteriores ${ }^{24}$. Precisamente, por esta razón, Hegel ve en la obra de arte una instancia en la que el hombre pone ante sí su naturaleza espiritual y se tiene a sí mismo como objeto. Ella es un espejo de su espiritualidad y, por ende, una objetivación de su autoconciencia (Jaeschke 393). Este es el sentido de la tesis según la cual el arte es una forma del autoconocimiento del espíritu y un fenómeno del espíritu absoluto ${ }^{25}$.

Solo desde esta perspectiva, a la vez, lógico-especulativa y filosófico-espiritual, se vuelve posible definir lo bello artístico como "el aparecer sensible de la idea" ${ }^{26}$. Cabe observar al respecto que, desde la publicación de los apuntes de los distintos ciclos de lecciones, la mencionada definición ha sido puesta en cuestión y descalificada como una grave alteración del contenido de las fuentes originales, atribuida a la interpretación e intervención de Hotho en la edición del texto. Los argumentos centrales sobre los que se apoya el veredicto recurren, ante todo, al hecho de que la misma no se encuentra en ninguno de los apuntes conservados y de que ella provocaría una supuesta desfiguración del sentido auténtico de la apariencia en el arte ${ }^{27}$. Ni uno ni otro argumento gozan de un sólido asidero. El primero de ellos resulta insuficiente: el hecho de que la fórmula no se halle presente como tal en ninguno de los apuntes conservados no prueba contundentemente

24 V. W XIII, pp. 205 y 207.

25 El concepto hegeliano de "espíritu absoluto" ha sido objeto de múltiples interpretaciones: ateístas, cristianas, panteístas, subjetivistas, antropológicas. Sin ánimo de entrar aquí en detalles polémicos, podemos precisar el asunto de manera general, con el fin de arrojar cierta luz sobre una de las tesis centrales de la estética de Hegel. El concepto del "espíritu absoluto", que surge como coronación de todo el desarrollo sistemático de la filosofía hegeliana, mienta una vida epistémica que rebasa la finitud de todas las formas del saber meramente subjetivo. El ser humano puede participar de esa vida en la medida en que interviene en experiencias supraindividuales, históricamente situadas, que nacen en el seno de un mundo ético determinado y que le permiten apropiarse del contenido espiritual realizado en su propio mundo histórico. Los tres fenómenos históricamente determinados de esta experiencia noética son para Hegel el arte, la religión y la filosofía. Mediante estas experiencias, el individuo se ve elevado por sobre su inmediatez y supera la finitud de las formas del saber meramente subjetivo, porque en ellas el pensar no se refiere a una objetividad exterior que se le presenta como extraña, sino que se trata de una autorrelación por la cual el espíritu humano se conoce en su misma interioridad fundamental y despierta en él la conciencia de su contenido, de su libertad esencial y de sus verdaderos intereses y fines espirituales.

26 W XIII, 151.

27 Cf., por ejemplo, el Prólogo de Gethmann-Siefert a la edición del apunte de Kehler en G. W. F. Hegel, Filosofía del arte o Estética, pp. 30 ss. 
que la misma no pueda atribuirse a Hegel ni que ella sea incompatible con las tesis centrales de su estética. Aun suponiendo que la definición constituya una reformulación introducida por Hotho, la pregunta decisiva debería escudriñar si ella resulta o no congruente con el contenido de las restantes tesis hegelianas sobre lo bello artístico. Según el segundo argumento antes referido, la definición tergiversaría el auténtico sentido del concepto de apariencia en el arte; mas, la debilidad del mismo reside en alegar una interpretación platonizante de la formulación de Hotho y, en especial, de los conceptos de "aparecer" (Scheinen) y de "apariencia" (Schein) ${ }^{28}$. No es posible encontrar una sola línea en las lecciones editadas, que induzca a una interpretación platonizante del término "Scheinen" presente en aquella definición. Más acertado parece recurrir, tal como hemos mostrado más arriba, al aparato técnico que establece la base y el fundamento del pensamiento hegeliano, esto es, a la lógica especulativa. Según ella, la apariencia consiste en una reflexión de lo lógico en y mediante lo sensible; de tal suerte, lo sensible mismo se muestra como mediación y no como mera existencia inmediata y exterior.

Cuando la mentada definición se interpreta a la luz de la lógica de la reflexión y del concepto esencial del "aparecer" y la "apariencia", entonces la fórmula resulta enteramente consecuente, por su contenido, con otras caracterizaciones de lo bello artístico cuya autenticidad no se discute. Aducimos aquí el ejemplo del parágrafo quingentésimo quincuagésimo sexto de la Enciclopedia de 1830, en el que se define el ideal como "la figura concreta" cuya "inmediatez natural es signo de la idea". El giro "signo de la idea" es equivalente con el de "aparecer de la idea". Podría objetarse, como hace Gethmann-Siefert (2005), que en

28 Ver, por ejemplo, el comentario de J. Domínguez a la crítica de Gethmann-Siefert en "Cultura y arte: una correspondencia en proceso. El ideal del arte en Hegel, correcciones a una interpretación establecida" (259 ss). En la página 261 del mencionado trabajo se lee: “[...] la formulación de Hotho pone el énfasis en la dirección de la idea a la apariencia, mantiene, por lo tanto, una jerarquía platonizante entre idea y apariencia, insostenible en Hegel, e inhibe, en cambio, la novedad de su pensamiento sobre el arte, cuyo trabajo más genuino no consiste tanto en sensibilizar la idea cuanto en hacer de lo sensible apariencia". Cuando uno se atiene a la lógica hegeliana de la reflexión como marco para la exégesis de la formulación de Hotho, en lugar de recurrir al pensamiento platónico, queda en evidencia que el proceso de 'sensibilizar la idea' y el de 'hacer de lo sensible apariencia' son uno y el mismo, porque 'hacer de lo sensible apariencia' significa, en rigor, descubrir en lo sensible una relación o reflexión que transparenta la potencia de lo lógico. 
este caso la expresión "signo de la idea" se refiere no al ideal como tal, sino a su inmediatez natural, a lo sensible en él (31). La objeción se resuelve con facilidad al advertir que el ideal no puede ser escindido respecto de su realidad sensible. Una impugnación derivada de la anterior invoca, además, un pasaje de los apuntes de Hotho, que enfatiza la apariencia como configuración propia de lo sensible en el arte. En él se lee:

...la superficie de lo sensible, el aparecer (Erscheinen) de lo sensible en cuanto tal, es el objeto del arte [...]. El espíritu solo quiere la superficie de lo sensible. Por lo tanto, en el arte, lo sensible está elevado a apariencia (Schein) y, con ello, el arte mismo se posiciona en el medio entre lo sensible como tal y el pensamiento puro ${ }^{29}$.

Desde este pasaje suele extraerse la conclusión de que "la definición de Hotho no debería expresar que el ideal sea la 'apariencia sensible de la idea, sino que sería la apariencia de lo sensible"; esta alteración probaría, además, "la inconciliable diferencia entre el pensamiento hegeliano y el de la Estética de 1835" (Gethmann-Siefert 31). Sin embargo, cabe observar que ambas formulaciones, a saber, "aparecer sensible de la idea” y "aparecer de lo sensible" resultan compatibles y conciliables entre sí, cuando se repara en el carácter subjetivo u objetivo de los genitivos de las expresiones mencionadas. Mientras que en la fórmula atribuida a Hotho ("aparecer sensible de la idea") el genitivo tiene un sentido subjetivo, que designa el sujeto que aparece (la idea), en la caracterización de los apuntes ("aparecer de lo sensible") el genitivo tiene un significado objetivo, puesto que refiere el medio configurado como apariencia (la inmediatez natural, lo sensible, se muestra como una reflexión positiva de lo lógico). El sentido último de ambas fórmulas no deja de ser por ello equivalente: las mismas remiten a los dos momentos de lo bello artístico como transfiguración de lo sensible en un medio de exposición (en una reflexión) de lo lógico, es decir, de la libertad. Al atender a tales consideraciones, la definición de Hotho no solo se muestra coherente con el resto de las tesis centrales sobre lo bello artístico, sino que, más decisivo aún, ella se comprueba como suficientemente avalada desde los fundamentos lógicos de la filosofía de Hegel.

29 G. W. F. Hegel, Vorlesungen über die Philosophie der Kunst, p. 20. 
Comprendida desde tales premisas, la belleza reside, sensu stricto, en la autonomía de lo lógico que se trasluce en la exterioridad empírica. Por este motivo, también en la naturaleza es posible hallar manifestaciones de lo bello, precisamente allí donde se evidencia su ser libre, su autonomía. Sin embargo, lo bello natural posee una jerarquía inferior a la de lo bello espiritual o artístico, y es solo un reflejo de este último: "lo bello natural aparece sólo como un reflejo de lo bello perteneciente al espíritu" ${ }^{30}$. En la naturaleza algo se nos aparece como bello solo cuando "vislumbramos [en sus configuraciones progresivas] una necesidad interna de articulación adecuada al concepto", es decir, su "racionalidad interna" ${ }^{31}$. La naturaleza se nos presenta como bella allí donde ella revela la teleología y la libertad del concepto. Esto explica además el hecho de que la naturaleza orgánica se nos figure siempre como "más bella" que la inorgánica, porque aquella evidencia de una manera más clara "la actividad interior" ${ }^{32}$, es decir, la negatividad del concepto.

Lo natural solo es bello por analogía con lo espiritual: cuando en él se anuncia lo espiritual, o cuando produce en el ánimo (un paisaje por ejemplo) un efecto espiritual, esto es, una especie de transformación de lo natural en espiritual. Lo bello no reside pues únicamente en la armonía, tampoco puede reducirse a la simetría, a la regularidad o a la legalidad, menos aún depende exclusivamente del material sensi$b^{33}$. Desde la perspectiva filosófica de Hegel, el concepto de "belleza" permanece reservado a la esfera del espíritu. Puede referirse también, como vimos, por analogía, a la naturaleza, pero solo porque ella es ya una presuposición del espíritu. A la naturaleza, sin embargo, y a lo bello natural en general, les falta el momento de la autorrelación que reconcilia de modo íntegro lo interno y lo externo. El concepto de "lo bello" se prueba, de tal manera, como perteneciente exclusivamente al reino del espíritu. Belleza es la transfiguración de lo natural, de lo sensible, de lo material, en una obra espiritual. Por este motivo, Hegel excluye lo bello natural de la estética, precisándola como una conside-

$30 \quad$ W XIII, 15.

31 W XIII, 173-174.

32 WXIII, 175.

33 V. W XIII, 178 ss. ("La belleza exterior de la forma abstracta y de la unidad abstracta del material sensible"). 
ración de lo bello artístico o del "ideal", entendido como "la reducción de la existencia exterior a lo espiritual” ${ }^{34}$.

Asimismo, ello justifica que, según Hegel, el principio de la imitación no pueda entenderse como el fundamento del arte. Él no puede ser definido desde una mera mímesis de la naturaleza, justamente porque su necesidad universal estriba en lo racional. Por lo mismo, tampoco puede ser explicado desde fines finitos, individuales y contingentes. No bastan para dar razón de la actividad artística ni los afectos, ni las pasiones, ni los sentimientos, mas tampoco la intención de instruir o transmitir contenidos morales. Bajo todas estas modalidades y orientaciones "no es, de hecho, arte libre e independiente, sino servil" ${ }^{35}$, y su obra no podría comprenderse como el espejo de la libertad. En tanto actividad verdaderamente libre, la finalidad del arte es él mismo, y solo cuando se lo entiende como libre y como autofinalidad se advierte también su naturaleza capaz de revelar la verdad:

Con ello se anula la posición falsa, según la cual el arte debería servir, mediante la instrucción y el perfeccionamiento, como medio para alcanzar fines morales y el fin moral último del mundo, de modo que él no tendría en sí mismo su fin sustancial sino que lo tendría en otra cosa. Lo equívoco reside aquí en el hecho de que la obra de arte ha de referirse a un otro, que se presenta para la conciencia como lo esencial, como lo que debe ser, de manera que la obra de arte tendría validez solo como un instrumento útil para la realización de esta finalidad válida independientemente para sí fuera del ámbito del arte. Frente a ello, debe afirmarse que el arte está llamado a descubrir la verdad en la forma de la configuración sensible, a exponer aquella oposición reconciliada [la del mundo de las necesidades y de la finitud con el mundo del pensamiento y la libertad] y que, por ende, tiene su fin último en sí mismo, en esta exposición y descubrimiento. Los otros fines, como la instrucción, la purificación, el perfeccionamiento [moral], la consecución de dinero, el afán de reputación y honor, no aportan nada al arte como tal y no determinan el concepto del mismo ${ }^{36}$. 
En suma, la obra de arte nace del espíritu, pero no está determinada meramente para ser usada o consumida, sino que está esencialmente destinada a una recepción también espiritual, precisamente porque ella pone ante nosotros "lo que acepta la razón y la verdad del espíritu"37. Ella es siempre para la subjetividad, y no solo para la subjetividad creativa del artista, sino también para la conciencia recreativa del que observa: "como objeto real y singular, la obra de arte no es para sí, sino para nosotros, para un público que la intuye y disfruta"38. De allí que Hegel la describa como "un diálogo con todos los que están presentes" ante ella. En esto consiste, por cierto, la "verdadera objetividad del arte"39: en el hecho de que "descubre el contenido sustancial" del espíritu y de que su "base permanente" reside en "lo humano del espíritu”, lo cual nos da la posibilidad de apropiárnosla más allá de sus peculiaridades históricas. Si bien "la obra de arte lleva siempre en sí particularidades" 40 , propias del tiempo y del lugar, de su época y de su pueblo, sin embargo, su contenido espiritual es universal y ello explica que sea "inmortal" 41: comprensible y disfrutable para los hombres de todos los tiempos.

\section{La tesis sobre el fin del arte}

La interpretación de lo bello artístico como "aparecer sensible de la idea" a la luz de la lógica de la esencia ofrece, además, un apoyo firme para dilucidar una de las tesis más provocativas y polémicas de la estética hegeliana, a saber, aquella según la cual el arte resulta indefectiblemente algo del pasado. En la Introducción de las Lecciones encontramos el siguiente juicio categórico acerca de la condición del arte:

...el arte ya no ofrece aquella satisfacción de las necesidades espirituales, que tiempos y pueblos más antiguos buscaron y encontraron solo en él [...]. En todas estas remisiones, el arte es y permanece para nosotros, según el lado de su determinación superior, como algo pasado. Por consiguiente, él ha perdido para nosotros la verdad y la vitalidad originales; más que afirmarse en la realidad su an- 
tigua necesidad y ocupar su puesto supremo, él se ha trasladado a nuestra representación. La obra de arte provoca ahora en nosotros, además del disfrute inmediato, a la vez, nuestro juicio, en la medida en que sometemos a nuestra consideración pensante el contenido de la obra de arte, sus medios de presentación y la adecuación o inadecuación entre ambos. La ciencia del arte es, por este motivo, mucho más necesaria en nuestro tiempo que cuando este ofrecía, ya en cuanto tal, la satisfacción plena. El arte nos invita ahora a la consideración pensante y no, por cierto, con el objetivo de producir nuevamente arte, sino de conocer científicamente lo que él es ${ }^{42}$.

Esta tesis queda ratificada al final de las Lecciones con la afirmación concluyente de la "disolución del arte" (Auflösung der Kunst) como desenlace inevitable de su mismo desarrollo conceptual e histórico:

En esta cumbre [la de la poesía dramática moderna], la comedia conduce a la disolución del arte en general. El fin de todo arte es la identidad producida por el espíritu, en la cual lo eterno, lo divino, lo verdadero en y para sí, se revela a nuestra intuición exterior, al ánimo y la representación, en un fenómeno y una figura reales. Mas, cuando la comedia presenta esta unidad solo en su autodestrucción, puesto que lo absoluto, que quiere producirse como realidad, ve anulada esta realización por los intereses devenidos ahora libres para sí en el elemento de la realidad efectiva y orientados solo hacia lo accidental y subjetivo, entonces el presente y la efectividad de lo absoluto ya no se destacan en una conciliación positiva con los caracteres y los objetivos de la existencia real. En lugar de ello, solo se hacen valer de forma negativa en la superación de todo lo que no corresponde a él [a lo absoluto] y, en esta disolución, solo la subjetividad se muestra como segura de sí misma y como asegurada en $\mathrm{si}^{43}$.

La declaración del carácter solo "pasado" del arte y la confirmación de su "disolución" son pronunciadas por Hegel nada menos que en tiempos de Beethoven, de Hölderlin, de Goethe, de Caspar Friedrich. ¿Qué suponen estas aserciones en relación con la obra de estos grandes genios del arte moderno? Y, ¿qué se desprende de ellas cuando se

42 W XIII, 24-26

$43 \mathrm{~W} X \mathrm{XV}, 572-573$. 
trata de comprender el estatus artístico de las obras producidas más tarde? ¿Cómo deberían interpretarse, atendiendo a ellas, las obras de Debussy, de R. Strauss, de Monet, de Cézanne, de Balzac, por nombrar aquí solo algunos ejemplos? La tesis del fin del arte, ¿exige negarles aquel estatus? De ningún modo, porque las afirmaciones de Hegel no significan, desde ningún punto de mira, negar la existencia del arte moderno, sino, antes bien, negarle la exclusividad y la preeminencia en relación con la promoción de la autoconciencia del espíritu: el arte "no es ya el ojo a través del cual el mundo moderno se reconoce" (Hoffmann 443$)^{44}$.

La metáfora referida aquí resulta enteramente pertinente, porque Hegel mismo describe el contenido universal del arte ("el ideal") mediante una analogía con el ojo: "el arte transforma cada una de sus figuras en un Argos de mil ojos, para que el alma y la espiritualidad interiores sean vistas en todos los puntos" ${ }^{\prime 4}$. El ideal es como un ojo, pues él mismo ve y permite además ver la interioridad, el "alma", a través de su contextura material y sensible. En efecto, el contenido que se expresa en la obra estriba en el haber de esa vida epistémica que Hegel llama "espíritu absoluto" y que, tal como el ojo, es capaz de ver y a la vez de revelar a la conciencia humana los supremos fines e intereses del espíritu en un momento específico de su desenvolvimiento histórico. No es entonces algo contingente $\mathrm{o}$ arbitrario, que resulte del simple capricho de la fantasía; tampoco es lo meramente visto, sino que él mismo es el "ojo" que observa: revela la naturaleza y el contenido del espíritu, su libertad, tal como es posible hacerlo en una determinada época histórica (precisamente, en este sentido él es "el aparecer de la idea"). Por eso Hegel se refiere a él como "el alma" universal, la subjetividad interior que se proyecta en la materia exterior.

Atendiendo a la mentada analogía, resulta claro que la afirmación del fin de arte equivale a la declaración de su absolución: la tesis propugna que el arte ha absuelto su tarea, su función histórico-espiritual, que era precisamente la de permitir que la autoconciencia reconociera e interiorizara el mensaje de la encarnación de la libertad (o, en tér-

44 Ante la evidencia que la exégesis de las fuentes reporta a su favor, adherimos en este punto a la lúcida interpretación propuesta por Th. S. Hoffmann y desarrollada en sus trazos generales en su obra ya citada (440-444).

45 W XIII, 203 ss.; cit. 203. 
minos lógicos, de la idea). El mensaje del arte, como "hacer sensible reconciliado del espíritu" ${ }^{46}$, fue siempre que lo objetivo, lo sensible, lo material - por ejemplo un objeto concreto, un color visible, un tono audible, una palabra hablada-, es capaz de ser "exterioridad asumida" y, con ello, un medio de expresión de la libertad (Hoffmann 442). Este mensaje ha sido interiorizado por la autoconciencia y, por esta razón, el arte ha cumplido ya con su tarea. Esto supone además que, en otra época - con mayor precisión, en la Época Clásica griega-, el arte fue efectivamente aquel "ojo", el medio constitutivo a través del cual "el espíritu se vuelve consciente de sus verdaderos intereses" ${ }^{\text {"77 }}$. La Grecia clásica no tenía opción; la tragedia, la escultura, eran el modo de expresión determinante de la autoconciencia histórica y de él dependían todas las otras instancias de determinación subjetivo-objetiva del espíritu. Para el mundo moderno, en cambio, puesto que él dispone de otras instancias igualmente determinantes de manifestación del saber, el arte es siempre algo elegido. Y, precisamente por esto, porque ya no es la instancia única de determinación subjetivo-objetiva del espíritu sino algo elegido, se abre una distancia reflexiva entre él y el hombre moderno, que convierte la relación entre ambos en una relación científica: "estamos más allá de poder adorar y venerar las obras de arte como algo divino; la impresión que ellas nos producen es de tipo reflexivo" ${ }^{\prime 4}$. Ilustrado con imágenes: en lugar de arrodillarnos ante una Madonna de Rafael, la conservamos en un museo; en lugar de configurarnos vitalmente desde y con la literatura y la música, concedemos premios de literatura y de música (Hoffmann 443).

En el mismo parágrafo quingentésimo quincuagésimo sexto de la Enciclopedia de 1830, Hegel insinúa la razón última de esta deposición del arte, al advertir su dispersión en tres factores diversos: la obra de existencia exterior, el sujeto que la produce y el sujeto que la contempla. En razón de su naturaleza empírica, el arte presenta una dispersión, una naturalidad e inmediatez que, conjugada con su historicidad intrínseca, da razón de su "disolución" o deposición final. Se demuestran como decisivos en este respecto, por un lado, el carácter esencialmente histórico del arte como fenómeno del espíritu; por otro, su in- 
mediatez, naturalidad y relativa arbitrariedad, debidas a su naturaleza sensible-material. Al definirse el arte como un fenómeno del espíritu absoluto, el mismo muestra una dimensión histórica cuya prueba reside en la dependencia de su contenido respecto del desarrollo de la autoconciencia del espíritu. Ahora bien, la naturalidad del arte solo se corresponde adecuadamente con un determinado nivel histórico en la formación de la autoconciencia, más precisamente con aquel nivel que resulta apropiado para una expresión sensible: el de la Grecia antigua. En ella, el saberse del espíritu presenta todavía una naturalidad, que se corresponde con su manifestación predominantemente artística; por este motivo, el arte resulta allí el elemento idóneo para expresar el haber espiritual y se erige como la instancia determinante de manera preeminente de todos los aspectos subjetivo-objetivos de la vida humana.

Asimismo, la naturalidad del arte se descubre como una limitación de las posibilidades de expresión de la autoconciencia del espíritu cuando su desarrollo histórico supera esas posibilidades. En ese momento, la obra de arte depone el privilegio de ser un objeto de culto. Este grado de desarrollo se alcanza para Hegel con el advenimiento de la religión cristiana. En el mundo cristiano, el contenido de la autoconciencia histórica conquista de modo progresivo un grado de determinación tal que ya no resulta acabadamente expresable mediante una figura sensible, sino que solo halla un medio adecuado en el elemento del pensar. Por supuesto, el arte no deja de existir en el mundo cristiano-moderno, pero pierde ya la preeminencia como factor determinante de la vida espiritual, pasando a ocupar un lugar, por así decir, secundario: "Luego de la aparición histórico-mundial de la religión cristiana, el arte ya no puede constituir el interés supremo del espíritu. Él permanece entonces como algo secundario" (Jaeschke 412).

En este sentido, la tesis hegeliana del fin y la disolución del arte no supone negar su existencia en el mundo moderno. Proclama, en cambio, el reconocimiento de que, conforme al desarrollo progresivo en la formación de la autoconciencia espiritual, el curso mismo de la historia ha abierto nuevas instancias de autointerpretación, de comprensión, expresión y proyección de los intereses espirituales, que van más allá de las posibilidades ofrecidas por el arte. El mismo se ha visto desplazado de su preponderancia como instancia determinante de la 
vida humana, primero en aras de la religión y, finalmente, en beneficio del saber conceptual, metódico y especulativo.

En suma, la tesis significa que, como consecuencia del curso histórico, el arte ya no determina la interioridad humana de un modo inmediato, lo cual no solo encuentra su traducción en aquella relación reflexiva antes indicada, sino también en el riesgo de una degradación del arte mismo: al haber absuelto su tarea, se abre la posibilidad de que "los intereses devenidos ahora libres" permanezcan "orientados solo hacia lo accidental y subjetivo". El peligro reside, en consecuencia, en que se vuelva un objeto de consumo, que sirva a intereses espurios, ajenos a él mismo, en que sea sometido a las necesidades y demandas de su tiempo, en que quede reducido a un mero instrumento. Bajo estas modalidades, tan frecuentes como celebradas en nuestro tiempo, el arte "no es independiente, no es libre, sino servil (dienende)" y, en consecuencia, no es "verdadero arte" 49 .

En todo verdadero poetizar, pensar y hacer, la libertad auténtica deja reinar a lo sustancial como un poder en sí, que al mismo tiempo es el poder más propio del pensar y del querer subjetivos, de modo que en la reconciliación plena de ambos ya no queda dilema alguno $^{50}$.

En este sentido, incluso hoy los verdaderos artistas disponen de la potestad de expresar, a su modo, el haber espiritual de su época y de descubrir nuevas posibilidades de autointerpretación del hombre, es decir, orientaciones inexploradas que abren instancias inéditas para un posicionamiento efectivamente libre ante las cosas.

\section{Conclusión}

Al concebir el arte como momento necesario del espíritu absoluto, la filosofía hegeliana ofrece una alternativa a las concepciones que subestiman la significación de la actividad artística como mero ornamento y como simple apariencia carente de verdad. En lugar de ello, el arte es presentado con el estatus de ser una de las formas superiores del saber alcanzado por el espíritu. Esta tesis implica lo siguiente, a saber:

49 W XIII, 20.

50 W XIII, 385. 
1. Que el arte no nace del solo juego arbitrario de la fantasía, sino que es una expresión de la estructura de la escisión y de la objetivación que arraiga en el concepto mismo del espíritu. Se trata entonces de una de las realizaciones sobresalientes de la estructura calificada por Hegel expresamente como racional, y esto supone que el arte posee una necesidad irreductible para el hombre, puesto que hunde sus raíces más profundas en su racionalidad y libertad.

2. Que el arte no es apariencia carente de verdad; por el contrario, es una figura del saber que transmite al hombre una autoconciencia histórica, que torna objeto de la conciencia las formas de la vida ética propia de un mundo y una racionalidad determinada, que las representa bajo el fenómeno de lo bello, influyendo, a su vez, de modo activo, en la creación y transformación de las manifestaciones objetivas de ese mundo. Por ello, el arte no es un simple ornato de la vida cultural del hombre: en sus obras los pueblos expresan el sentido de la vida y, por tal motivo, también mediante ellas la existencia humana adquiere una cierta orientación.

En suma, lo que caracteriza al arte como momento del espíritu absoluto es, según la visión especulativa de Hegel, la revelación de dimensiones nuevas del hombre, la participación en la autoconciencia histórica y en la creación continua del hombre por el hombre (Garaudy 383).

\section{Bibliografía}

Aristóteles, Poética, ed. Trilingüe de V. García Yebra. Madrid: Gredos, 2010.

Arndt, Andreas, Krück, Günter \& Zovko, Jure (Eds.). Gebrochene Schönheit. Hegels Ästhetik - Kontexte und Rezeptionen. Berlín: De Gruyter, 2014.

Baumgarten, Alexander Gottlieb. Aesthetica. Traiecti cis Viadrum. Impens. Ioannis Christiani Kleyb, 1758. Disponible en: www. archive.org

Burke, Edmund. A philosophical enquiry into the origin of our ideas of the sublime and beautiful. Oxford: Oxford University Press, 1990. Disponible en: http://search.ebscohost.com/login.as px?direct=true \&scope $=$ site $\& d b=$ nlebk $\& d b=$ nlabk $\& A N=257$ 862.E 
Debernardi Cárcamo, Italo. "Las lecciones sobre estética de Hegel: discrepancias fundamentales entre la edición de Hotho y los Nachschriften”. Aisthesis 67 (2020): 9-30.

Domínguez, Javier. "Cultura y arte: una correspondencia en proceso. El ideal del arte en Hegel, correcciones a una interpretación establecida", en Acosta, M. R. y Díaz, J. A. La nostalgia de lo absoluto: pensar a Hegel hoy. Bogotá: Universidad Nacional de Colombia, 2008. 247-271.

Garaudy, Roger. Dios ha muerto. Buenos Aires: Platina, 1965.

Gethmann-Siefert, Annemarie. Einführung in Hegels Ästhetik. München: Wilhelm Fink, 2005.

Hegel, Georg Wilhelm Friedrich. Filosofía del arte o Estética. Verano de 1826. Apuntes de F. C. H. V. von Kehler. Madrid: ABADA, 2006.

Georg Wilhelm Friedrich Hegel's Werke. Vollständige Ausgabe durch einen Verein von Freunden des Verewigten. Bände X.1, $X .2, X .3$. Berlin: Duncker und Humblot, 1835-1838; $1842_{2}$.

. Gesammelte Werke, ed. de la Rheinisch-Westfälischen Akademie der Wissenschaften en cooperación con la Deutsche Forschungsgemeinschaft. Hamburgo: Meiner, 1968 ss. (= GW).

. Gesammelte Werke. Band 28.1: Vorlesungen über die Philosophie der Kunst I. Nachschriften zu den Kollegien der Jahre 1820/21 und 1823. Hamburg/Düsseldorf: Meiner, 2015.

Gesammelte Werke. Band 28.2: Vorlesungen über die Philosophie der Kunst II. Nachschriften zum Kolleg des Jahres 1826. Hamburg: Meiner, 2018.

Gesammelte Werke. Band 28.3: Vorlesungen über die Philosophie der Kunst III. Nachschriften zum Kolleg des Wintersemesters 1828/1829. Hamburg: Meiner, 2020.

Lecciones sobre filosofía de la Religión. 1. Introducción y concepto de la religión. Madrid/Buenos Aires: Alianza, 1984.

Philosophie der Kunst. Frankfurt am Main: Suhrkamp, 2004.

Philosophie der Kunst oder Ästhetik. München: Wilhelm Fink, 2004.

Vorlesungen über Ästhetik. Berlin 1820/21. Eine Nachschrift. Frankfurt am Main: Peter Lang, 1995.

. Vorlesungen über die Philosophie der Kunst. Hamburg: Meiner, 1998. 
Vorlesungen über die Philosophie der Kunst (1823). Hamburg: Meiner, 2007.

. Werke in zwanzig Bänden, ed. de E. Moldenhauer y K. M. Michel. Fránkfort del Meno: Suhrkamp, 1970 ss. (= W).

Hilmer, Brigitte. Scheinen des Begriffs. Hegels Logik der Kunst. Hamburgo: Meiner, 1997.

Hoffmann, Thomas Sören. Georg Wilhelm Friedrich Hegel. Eine Propädeutik. Wiesbaden: Marix, 2004.

Horacio, Arte Poética, trad. de J. A. González. Madrid: Cátedra, 2012.

Jaeschke, Walter. Hegel-Handbuch. Stuttgart: J. B. Metzler, 2016 (=HB).

Kant, Immanuel. Kant's Gesammelte Schriften „Akademieausgabe“, ed. de la Königlich Preußische Akademie der Wissenschaften. Berlín: Reimer/De Gruyter, 1900 ss. (= AA). Disponible en: https://korpora.zim.uni-duisburg-essen.de/kant/verzeichnisse-gesamt.html

Longino. Sobre lo sublime. Madrid: Gredos, 2008.

Meyer, Heinrich. Geschichte der bildenden Künste bei den Griechen. Dresden: Waltersche Hofbuchhandlung, 1824.

Sandkühler, Hans Jörg (Ed.). Handbuch Deutscher Idealismus. Stuttgart/Weimar: J. B. Metzler/Springer, 2005.

Schelling, Friedrich Wilhelm Joseph. System des transzendentalen Idealismus. Tubinga: J. G. Cotta, 1800. Recuperado de www. archiv.org

Schiller, Friedrich. Über die ästhetische Erziehung des Menschen in einer Reihe von Briefen. Text, Materialien, Kommentar, ed. de W. Düsing. Múnich: Hanser, 1981.

Schlegel, Friedrich. Poesía y filosofía. Madrid: Alianza Universidad, 1995. 